\section{Optimal Spray Application Rates for Ornamental Nursery Liner Production}

\author{
Heping Zhu ${ }^{1}$, James Altland, Richard C. Derksen, and \\ Charles R. Krause
}

ADDITIONAL INDEX WORDS. bareroot stock, environment, nursery sprayer, pest management, spray coverage, spray deposition

SumMARY. Spray deposition and coverage at different application rates for nursery liners of different sizes were investigated to determine the optimal spray application rates. Experiments were conducted on 2- and 3-year-old 'Autumn Spire' red maple (Acer rubrum) liners. A traditional hydraulic sprayer with vertical booms between tree rows was used to apply the spray applications. Application rates were 10, 20, 30 , and $40 \mathrm{gal} / \mathrm{acre}$ for the 2-year-old liners and were $20,40,60$, and $80 \mathrm{gal} / \mathrm{acre}$ for the 3-year-old liners. Nylon screens were used to collect spray deposition of a fluorescent tracer dissolved in water, and water-sensitive papers were used to quantify spray coverage inside canopies. Spray deposition, coverage, and droplet density inside both 2 - and 3 -year-old liner canopies increased as the application rate increased. The minimum rates to spray 6.6-ft-tall, 2 -year-old 'Autumn Spire' red maple liners and 8.7-ft-tall, 3-year-old liners were 20 and 40 gal/acre, respectively. An exponential equation was derived from these results to estimate the spray application rate required for different tree liner heights and to minimize excessive chemical use in rapidly growing tree liners.

$\mathrm{T}$ There are over 1400 liner nurseries in the United States with over $\$ 395$ million in sales in 2009 [U.S. Department of Agriculture (USDA), 2010]. In this production system, small liners (3- to 20 -inch tall) are densely planted at a rate of 7000 to 10,000 plants per acre. Many tree species reach a height of 6 to $10 \mathrm{ft}$ during 1 to 3 years (Fare, 2006). The high density of liner plantings can aggravate the severity and incidence of insect infestations and diseases in liner production. In the Pacific northwestern United States, where much of bareroot liner production occurs, over 27 genera of arthropods [e.g., ambrosia beetles (Curculionidae), caterpillars (Limacodidae), leafhoppers (Cicadellidae), etc.] (Hollingsworth, 2010) and more than a dozen diseases [e.g. powdery mildew (Erysiphaceae),

U.S. Department of Agriculture-Agricultural Research Service, Application Technology Research Unit, 1680 Madison Avenue, Wooster, OH 44691

We gratefully acknowledge the generous donations of land, spray equipment, personnel, and crops for this research from Mr. Ross Dumdi, production manager of Bailey Nurseries, Inc., Yamhill, OR. We thank Adam Clark, Keith Williams, Andy Doklovic, and Tony Karcher for their technical assistance in the field experiments, Leslie Morris for the deposition analysis, and Steven Sigler for the water-sensitive paper analysis.

Mention of proprietary product or company is included for the reader's convenience and does not imply any endorsement or preferential treatment by USDA-ARS.

${ }^{1}$ Corresponding author. E-mail: heping.zhu@ars.usda. gov. anthracnose (Colletotrichum spp.), crabapple scab (Venturia inaequalis), etc. (Ingham et al., 2010)] are common.

Insecticides and fungicides are used routinely to suppress and control pests and diseases. In 2006, chemicals used in liner production in California, Florida, Michigan, Oregon, Pennsylvania, and Texas were $\approx 21,000 \mathrm{lb}$ for insecticides and $157,900 \mathrm{lb}$ for fungicides (USDA, 2007). To maximize the effectiveness of pest management strategies, confirmation of the actual spray coverage and spray deposition on targets under field conditions is required (Bache and Johnstone, 1992). The spray coverage required to effectively control pests has been studied for other crops (Falchieri et al., 1995; Fisher and Menzies, 1976; Hewitt and Meganasa, 1993; Washington, 1997) but not for ornamental nursery liners. Without definitive guidelines for the requisite amounts of spray to achieve adequate deposition and coverage, the result will be either reduced pesticide coverage from less than desirable spray volume or off-target movement of the pesticide because of excessive spray volume.

No spray equipment or spray application method currently exists that can apply chemicals to the numerous varieties of nursery crops. Several reports on using spray systems for nursery shade tree production are available (Derksen et al., 2004; Krause et al., 2004; Zhu et al., 2006, 2008), but none of them addressed the problem of how to optimize application rates for use in field-grown tree liner production. In response to an onset of pest infestations, liner spray applicators must make calculated decisions within a very narrow time window on how much pesticide and spray volume will be needed for economical control. Accordingly, they often simply use a "best guess" practice that usually applies excessive amounts of pesticides for pest control. This "best guess" practice is to spray liners to the point of runoff or saturated target areas with pesticides. The "point of runoff" method was tested with water as the carrier alone for its effectiveness to insure adequate spray deposition and coverage inside the canopies of nursery trees, and exceeded the amount of pesticide required for economical pest control by at least four times (Zhu et al., 2006, 2008). Consequently, the application of spray is inefficient and crops are oversprayed.

\begin{tabular}{llll}
\hline $\begin{array}{l}\text { Units } \\
\begin{array}{l}\text { To convert U.S. to SI, } \\
\text { multiply by }\end{array}\end{array}$ & U.S. unit & SI unit & $\begin{array}{l}\text { To convert SI to U.S., } \\
\text { multiply by }\end{array}$ \\
\hline 0.4047 & $\mathrm{acre}(\mathrm{s})$ & $\mathrm{ha}$ & 2.4711 \\
29.5735 & $\mathrm{fl} \mathrm{oz}$ & $\mathrm{mL}$ & 0.0338 \\
31.8327 & $\mathrm{fl} \mathrm{oz} / \mathrm{ft}^{2}$ & $\mu \mathrm{L} \cdot \mathrm{cm}^{-2}$ & 0.0314 \\
0.3048 & $\mathrm{ft}$ & $\mathrm{m}$ & 3.2808 \\
3.7854 & $\mathrm{gal}$ & $\mathrm{L}$ & 0.2642 \\
9.3540 & $\mathrm{gal} / \mathrm{acre}$ & $\mathrm{L} \cdot \mathrm{ha}^{-1}$ & 0.1069 \\
2.54 & inch $(\mathrm{es})$ & $\mathrm{cm}$ & 0.3937 \\
6.4516 & inch & $\mathrm{cm}$ & 0.1550 \\
0.4536 & $\mathrm{lb}$ & $\mathrm{kg}$ & 2.2046 \\
1 & micron & $\mu \mathrm{m}$ & 1 \\
1.6093 & $\mathrm{mph}$ & $\mathrm{km} \cdot \mathrm{h}^{-1}$ & 0.6214 \\
7.4892 & $\mathrm{oz} / \mathrm{gal}$ & $\mathrm{g} \cdot \mathrm{L}^{-1}$ & 0.1335 \\
6.8948 & $\mathrm{psi}$ & $\mathrm{kPa}$ & 0.1450 \\
$\left({ }^{\circ} \mathrm{F}-32\right) \div 1.8$ & ${ }^{\circ} \mathrm{F}$ & ${ }^{\circ} \mathrm{C}$ & $\left(1.8 \times{ }^{\circ} \mathrm{C}\right)+32$
\end{tabular}


Sprayers suitable for field-grown tree liner applications are few in number. The high ground clearance with vertical booms and over-the-row frame sprayer is commonly used to accommodate the relatively small canopy of liners and narrow row spacing. The spray booms are suspended between two rows of liners and the multiple nozzles from two parallel vertical booms simultaneously apply the spray horizontally to the both sides of the liners. The advantages of this sprayer are that multiple rows are sprayed at the same time and differences in tree height can be accommodated by turning the top nozzles on or off. The disadvantage is the excessive amount of time for applicators to frequently turn on or off nozzles manually to match canopy height across several rows. Also, the adjustments of spray nozzles for tree height are often ignored when the demand for spray applications must be completed in a short time and thus contribute to unnecessary sprays. Lastly, a higher than needed application rate is often used at any one-time spray when applicators are hindered in their determination of the proper rates for application because of the rapid growth of liners. However, if guidelines were available to optimize the application rate for pest control, growers could minimize excessive pesticide use in liner production.

The objectives of this research were to quantify the amount of spray deposition and coverage inside nursery liner canopies from over-the-row frame vertical boom sprayer, to determine its optimal application rates, and to establish a spray rate model for different size liners with similar canopy shapes, in an effort to increase spray application efficiency and achieve real cost savings for liner growers.

\section{Materials and methods}

'Autumn Spire' red maple liners were used as the test species in two plots. Liners used in this study were located on a production nursery in Yamhill, OR, and were grown using production techniques typical of this region. One plot each was planted with 2- and 3-year-old liners, respectively. In both plots, spacing between liners within a row was $1.5 \mathrm{ft}$ and between liner rows was $4 \mathrm{ft}$. The average height, height of the lowest branch from the soil, diameter of the stem (caliper) at 8 inches aboveground, and the average individual leaf area of 2- and 3-year-old liners are listed in Table 1. The stems of the 2-year-old liners had about four branches of $\approx 8$ inches in length. The canopy of 2-year-old liners was comparatively open (Fig. 1A). However, the stems of 3 -year-old liners had $\approx 14$ branches that were $\approx 10$ inches in length (Fig. 1B). Canopies of 3-yearold liners were denser than the 2-yearold liners.

A hydraulic, high ground clearance sprayer (TR-4 Tracker; GK Machine, Donald, OR) was used for the test (Fig. 1). The sprayer was equipped with a sprayer controller (SCS 450 NVM; Raven Industries, Sioux Falls, SD), a flow meter (60P, Raven Industries), four directional valve units (TeeJet 460Z; Spraying Systems, Wheaton, IL), two 200-gal spray tanks, and a centrifugal pump (9303C-HM4C-SP; Hypro, New Brighton, $\mathrm{MN}$ ). The pump was capable of producing maximum pressure of $180 \mathrm{psi}$ and a maximum flow rate of $95 \mathrm{gal} / \mathrm{min}$. The desired flow rate based on actual demands was obtained by changing the speed of the hydraulic driven centrifugal pump. A global positioning system was mounted on the sprayer to monitor travel speed which in turn relayed this information to the controller to adjust nozzle flow rates at a desired application rate. The sprayer was fitted with a 48 -ft-long horizontal frame to support 12 -section vertical booms. Each section consisted of two vertical booms that incorporated three opposing pairs of nozzles equally spaced at $2 \mathrm{ft}$ along the vertical booms. Each row of liners was sprayed by opposing pairs of nozzles. The adjustable support frame of the vertical boom was capable of accommodating the variable liner heights.

Application rates were 10, 20, 30, and $40 \mathrm{gal} / \mathrm{acre}$ for 2 -year-old liners and were $20,40,60$, and $80 \mathrm{gal} / \mathrm{acre}$ for 3 -year-old liners. Number of active nozzles and their operating parameters used to produce the four application rates are listed in Table 2. Weather conditions for each test treatment are also listed in Table 2. Nozzles were $110^{\circ}$ flat fan pattern Turbo Teejet tips (Spraying Systems). These nozzles reduced overspray drift and nozzle plugging from large particulates and had a larger flow path and exit orifice size than conventional flat fan nozzles. The operating pressures were adjusted to calibrate nozzle flow rates with the application rate (Table 2). The travel speed was $3 \mathrm{mph}$, except for 2 -year-old liners at $10 \mathrm{gal} / \mathrm{acre}$, which used 4 $\mathrm{mph}$. For each test, only four rows were simultaneously sprayed. The nozzles for other eight rows were shut off. Liners in the second sprayed row were sampled for deposition and coverage.

For tests on 2-year-old liners, only the two lower nozzles of each vertical boom were operational to spray each row (Fig. 2). The heights

Table 1. Average canopy height, lowest branch height, caliper, and leaf area for the size measurements of 2- and 3-year-old 'Autumn Spire' red maple liners when tests were conducted.

\begin{tabular}{lcccc}
\hline $\begin{array}{l}\text { Liner } \\
\text { age }(\mathrm{yrs})\end{array}$ & $\begin{array}{c}\text { Canopy } \\
\text { ht }(\mathrm{ft})^{\mathrm{z}}\end{array}$ & $\begin{array}{c}\text { Lowest branch } \\
\text { ht }(\mathrm{ft})\end{array}$ & $\begin{array}{c}\text { Caliper at 8-inch } \\
\text { ht (inches) }\end{array}$ & $\begin{array}{c}\text { Leaf area } \\
\left(\text { inch }^{2}\right)^{\mathrm{z}}\end{array}$ \\
\hline 2 & 6.6 & 2.0 & 0.6 & 7.75 \\
3 & 8.7 & 2.6 & 0.9 & 7.75 \\
\hline
\end{tabular}

${ }^{2} \mathrm{lft}=0.3048 \mathrm{~m}, \mathrm{l}$ inch $=2.54 \mathrm{~cm}, \mathrm{l}$ inch $^{2}=6.4516 \mathrm{~cm}^{2}$

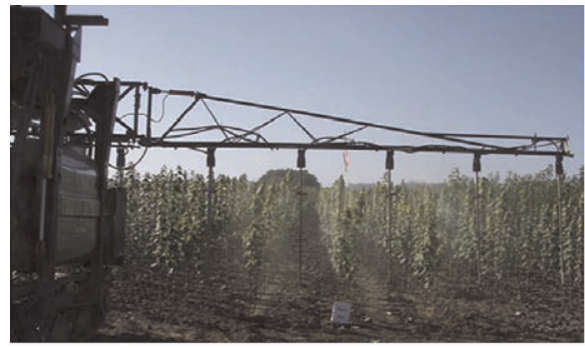

A

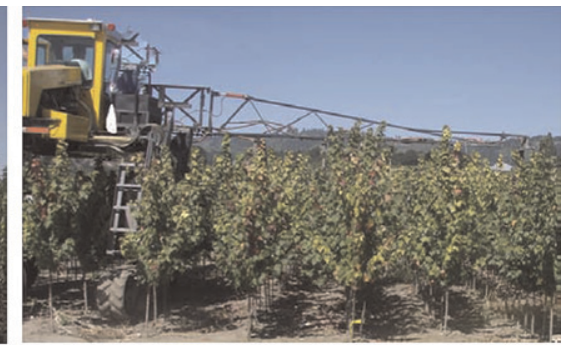

B
Fig. 1. Spray deposition and coverage test on (A) 2-year-old and (B) 3-year-old 'Autumn Spire' red maple liner plots with the high ground clearance sprayer (TR-4 Tracker; GK Machine, Donald, OR). 
Table 2. Spray application variables [application rate (AR), nozzle tip, number of nozzles (NN) used, operating pressure (OP), nozzle flow rate $(\mathrm{Q})$, and sprayer travel speed (V)] and weather conditions [wind speed (W), ambient temperature $(\mathrm{T})$, and relative humidity $(\mathrm{RH})]$ for field tests in 2 - and 3-year-old 'Autumn Spire' red maple liner plots.

\begin{tabular}{llllcccccc}
\hline $\begin{array}{l}\text { Liner } \\
\text { age (yrs) }\end{array}$ & $\begin{array}{c}\text { AR } \\
(\text { gal/acre })^{\mathbf{z}}\end{array}$ & $\begin{array}{c}\text { Nozzle } \\
\text { tip }^{\mathbf{y}}\end{array}$ & $\begin{array}{c}\text { NN } \\
(\mathbf{n o .})\end{array}$ & $\begin{array}{c}\text { OP } \\
(\mathbf{p s i})^{\mathbf{z}}\end{array}$ & $\begin{array}{c}Q \\
\left(\mathbf{L} \cdot \mathbf{m i n}^{-1}\right)^{\mathbf{z}}\end{array}$ & $\begin{array}{c}V \\
(\mathbf{m p h})^{\mathbf{z}}\end{array}$ & $\begin{array}{c}W \\
(\mathbf{m p h})\end{array}$ & $\begin{array}{c}T \\
\left({ }^{\circ} \mathbf{C}\right)^{\mathbf{z}}\end{array}$ & $\begin{array}{c}\mathrm{RH} \\
(\%)\end{array}$ \\
\hline 2 & 10 & TT11001 & 4 & 30 & 0.32 & 4 & 1.8 & 18 & 52 \\
2 & 20 & TT110015 & 4 & 30 & 0.46 & 3 & 1.0 & 18 & 50 \\
2 & 30 & TT11002 & 4 & 35 & 0.70 & 3 & 0.9 & 18 & 47 \\
2 & 40 & TT110025 & 4 & 40 & 0.92 & 3 & 3.2 & 21 & 42 \\
3 & 20 & TT11001 & 6 & 30 & 0.31 & 3 & 2.3 & 26 & 31 \\
3 & 40 & TT11002 & 6 & 30 & 0.63 & 3 & 3.5 & 27 & 26 \\
3 & 60 & TT110025 & 6 & 40 & 0.90 & 3 & 3.9 & 27 & 21 \\
3 & 80 & TT11003 & 6 & 50 & 1.18 & 3 & 5.9 & 27 & 20 \\
\hline
\end{tabular}

${ }^{\mathrm{z}} \mathrm{l} \mathrm{gal} / \mathrm{acre}=9.3540 \mathrm{~L} \cdot \mathrm{ha}^{-1}, \mathrm{l} \mathrm{psi}=6.8948 \mathrm{kPa}, \mathrm{l} \mathrm{L}=0.2642 \mathrm{gal}, \mathrm{l} \mathrm{mph}=1.6093 \mathrm{~km} \cdot \mathrm{h}^{-1},{ }^{\circ} \mathrm{F}=\left(1.8 \times{ }^{\circ} \mathrm{C}\right)+32$ ${ }^{y}$ Catalog numbers of nozzle tips manufactured by Spraying Systems (Wheaton, IL).

Sampler locations inside canopy
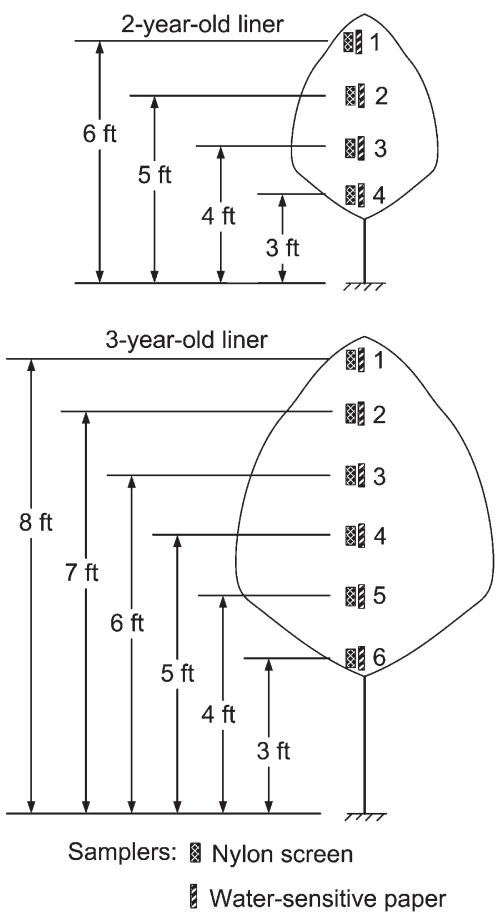

Test design for 2- and

3-year-old liner plots

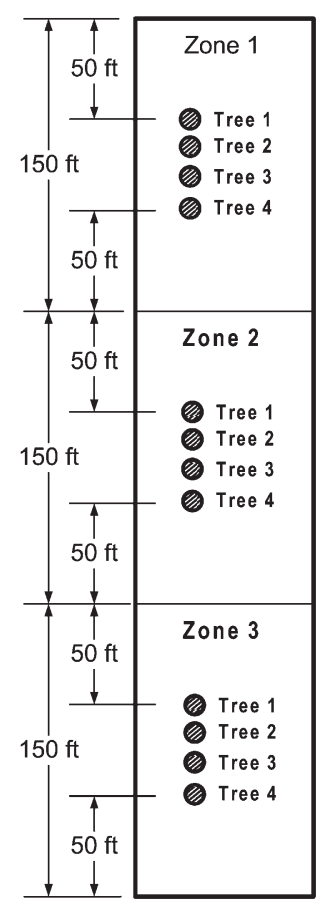

Fig. 2. Test plot design and locations of spray samplers (nylon screens and watersensitive papers) inside canopies and in a tree row for 2- and 3-year-old 'Autumn Spire' red maple liners; $1 \mathrm{ft}=0.3048 \mathrm{~m}$.

of these two nozzles were 3 and $5 \mathrm{ft}$ above the ground to match the canopy. For the test with 3-year-old liners, all three nozzle sets were used (Fig. 2) and the heights of these nozzles were 4,6 , and $8 \mathrm{ft}$ above the ground to accommodate the larger liner size.

A section ( $450 \mathrm{ft}$ in length) from each of 2- and 3-year-old liner plots was selected for each application rate treatment (Fig. 2). The section was equally divided into three zones to section for spray samples, and the last 50 - $\mathrm{ft}$ section for sprayer deceleration (Fig. 2). The sprayer started at the beginning and stopped at the end of each zone. Four individual liners were randomly selected from the middle of each 50 - $\mathrm{ft}$ section for placement of samplers to measure the amount of spray deposits and coverage. The samplers consisted of a $2 \times 2$-inch monofilament nylon screen (Filter Fabrics, Goshen, IN) to simulate leaves for collection of foliar spray deposits discharged from nozzles on both sides and two $2 \times 3$-inch water-sensitive papers (Syngenta Crop Protection, Basel, Switzerland) to collect the spray deposits for measuring spray coverage. They were held by a set of electric clips on tree limbs and placed at $3,4,5$, and $6 \mathrm{ft}$ aboveground for 2 -year-old liners and placed at $3,4,5,6,7$, and $8 \mathrm{ft}$ aboveground for 3 -year-old liners (Fig. 2 ). The screen had a nominal porosity of $\approx 56 \%$ or fiber frontal area percentage of $44 \%$. The frontal area of the samplers faced the spray nozzles. The two water-sensitive papers were set back to back to intercept spray deposits discharged from nozzles on both sides. The sprayer direction of travel was from north to south for 2-year-old liners and was from south to north for 3 -year-old liners.

The spray was a mixture of $3 \mathrm{~g} \cdot \mathrm{L}^{-1}$ of a fluorescent tracer (Brilliant Sulfaflavine; MP Biomedicals, Aurora, $\mathrm{OH}$ ) and water. All samplers were collected 15 min after each spray. The nylon screens were placed in $125-\mathrm{mL}$ plastic bags stored in opaque boxes, and water-sensitive papers were stored in paper bags.

Screens were brought to the laboratory and washed free of the fluorescence tracer with purified water. The amount of spray deposition on targets was based on the fluorescent intensity of each wash solution, which was then converted to the volume of spray per unit area in microliters per square centimeter. Fluorescent intensity of each wash solution was determined with a luminescence spectrometer (LS 50B; Perkin-Elmer, Seer Green, UK) at an excitation wavelength of $460 \mathrm{~nm}$.

The calculation of percentage spray coverage was based on the ratio between the area covered by spray deposits and the total area of a watersensitive paper. The number of droplets per unit area was also reported as 
the droplet density on the target. The spray coverage on each water-sensitive paper was analyzed with a computer imaging system, which included a handheld business card scanner (ScanShell 800N; CSSN, Los Angeles, CA), a laptop computer, and a customdesigned software "DepositScan" (Zhu et al., 2010). The resolution for the image analysis was 600 dots/inch.

The droplet size from each nozzle type was measured with a particle/ droplet image analysis system (VisiSizer and PIV; Oxford Lasers, Didcot, $\mathrm{UK}$ ) in the laboratory. The system was able to measure droplet diameters from 21 to $1732 \mu \mathrm{m}$. Droplet samples were taken 20 inches below the nozzle orifice and across centerline of the spray pattern. At least 10,000 droplets were sampled for each nozzle test. The droplet size spectrum including $D_{\text {v0.1 }}, D_{\text {V0.5 }}, D_{\text {v0.9.9 }}$, and mean volume droplet diameter $\left(D_{\mathrm{m}}\right)$ were reported. $D_{\text {Vo.1 }}, D_{\text {V0.5 }}$, and $D_{\text {V0.9 }}$ represent the distribution of the droplet diameters such that droplets with a diameter smaller than $D_{\mathrm{V} 0.1}, D_{\mathrm{V} 0.5}$, and $D_{\mathrm{V} 0.9}$ compose $10 \%, 50 \%$, and $90 \%$ of the total liquid volume, respectively. $D_{\mathrm{m}}$ was calculated from the total volume of the spray divided by the total number of droplets.

To compare differences in spray deposition and coverage among the application rates, samples from entire trees in three zones were grouped to calculate means. For differences in spray deposition and coverage among tree heights, samples at each height on four trees in three zones were grouped to calculate means. Spray deposition and coverage data were first analyzed by one-way analysis of variance using statistical software (ProStat version 3.8; Poly Software International, Pearl River, NY) to test the null hypothesis that all treatments had equal means. If the null hypothesis was rejected, Fisher's least significant difference (LSD) multiple comparison test was used to determine differences among means. All differences were analyzed at the 0.05 level of significance. If significant differences in means were obvious by comparing LSD values, only the standard deviations which emphasized the variations of the treatments would be reported after the mean value of each treatment.

\section{Results and discussion}

SPRAY DEPOSIT. For both 2-yearold (Fig. 3A) and 3-year-old (Fig. 3B) liners, the mean amount of spray deposits on targets inside a canopy increased linearly as the application rate increased. Also, deposits nearly doubled when the application rate was doubled in both 2- and 3-year-old liners. At the same application rates, the spray deposits on targets of 2-yearold liners were higher than the spray deposits on targets of 3-year-old liners. For example, the mean amount of spray deposit on targets inside the 2 -year-old canopy was 0.69 and 1.30 $\mu \mathrm{L} \cdot \mathrm{cm}^{-2}$ at $20-$ and $40-\mathrm{gal} /$ acre application rates, respectively. With the same application rates, the mean amount of spray deposit on targets inside the 3 -year-old canopy was 0.27 and 0.69 $\mu \mathrm{L} \cdot \mathrm{cm}^{-2}$, respectively. Thus, the application of the same amount of spray deposit on 3-year-old liners requires double the application rate as on 2 -year-old liners.

Table 3 shows the mean spray deposit, coverage, and droplet density at different heights for four application rates within canopies of 2 -yearold liners. At a given application rate, the mean amount of spray deposits on targets at 4-, 5-, and 6-ft heights for 2 -year-old liners were similar. However, the spray deposition of lower part of canopy at $3 \mathrm{ft}$ above the ground was less than the spray deposition at the upper three heights of the canopy (Table 3 ). This distribution indicated a relatively uniform spray deposition pattern across upper canopy heights and reflected the greater amount of foliage at the bottom than at the upper part of the canopy.

For 3-year-old liners, the mean spray deposit at six different heights inside the canopy was similar at the 20 -gal/acre application rate and significantly different at the three higher application rates (Table 4). The mean amount of spray deposition on targets at 7- and 8-ft heights for the 40-, 60-, and $80-\mathrm{gal} /$ acre application rates was $2.3,1.8$, and 1.6 times higher, respectively, than at 3-, 4-, 5-, and 6-ft heights. This reduction in deposition was due to the presence of more foliage at bottom part of the liner

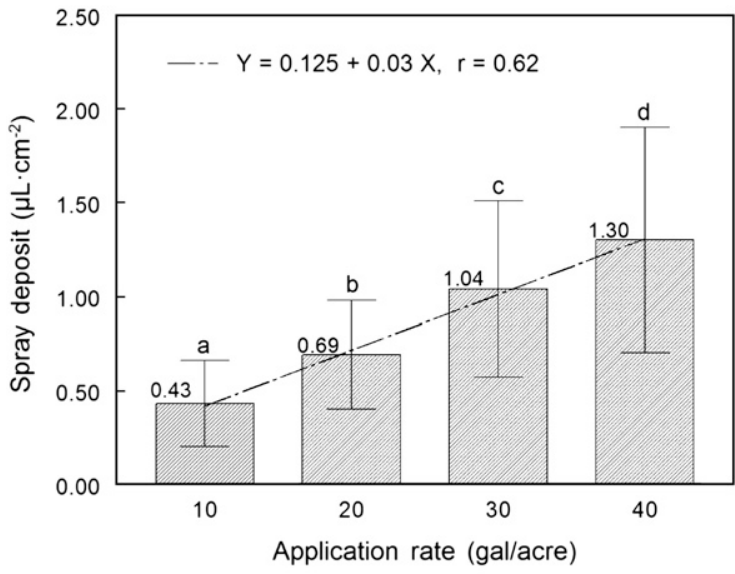

A

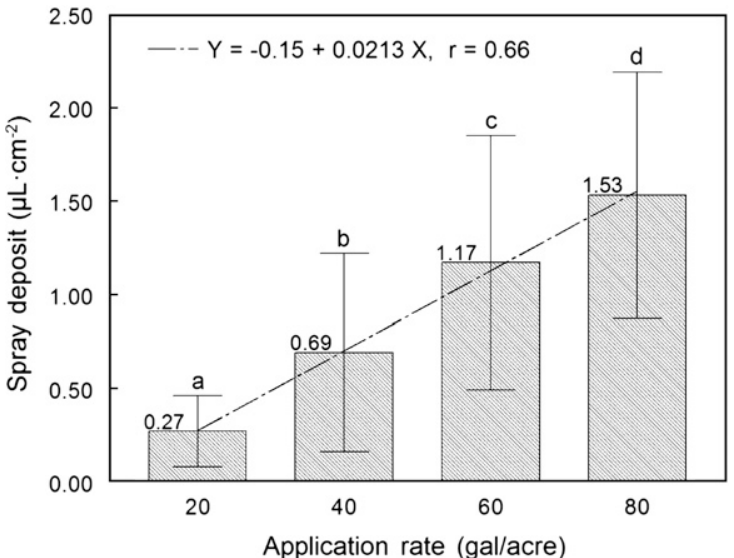

$\mathrm{B}$

Fig. 3. Mean spray deposits on samplers at different heights inside canopies for four application rates to treat (A) 2-year-old and (B) 3-year-old 'Autumn Spire' red maple liners. Error bars are sD for each treatment. Different lowercase letters on error bars represent significant differences in means at $P<0.05 ; Y=$ spray deposit (microliters per square centimeter), $X=$ application rate (gallons per acre), $r=$ coefficient of determination; $1 \mathrm{gal} / \mathrm{acre}=9.3540 \mathrm{~L} \cdot \mathrm{ha}^{-1}, 1 \mu \mathrm{L} \cdot \mathrm{cm}^{-2}=0.0314 \mathrm{fl} \mathrm{oz} / \mathrm{ft}^{2}$. 
Table 3. Mean spray deposit, coverage, and droplet density at four different target heights inside 2-year-old 'Autumn Spire' red maple canopies for four application rates (ARs).

\begin{tabular}{lcccc}
\hline $\begin{array}{c}\text { Target } \\
\text { ht }(\mathbf{f t})^{\mathrm{z}}\end{array}$ & $\begin{array}{c}\text { AR } \\
(\mathrm{gal} / \mathrm{acre})^{\mathrm{z}}\end{array}$ & $\begin{array}{c}\text { Spray deposit } \\
{[\text { mean } \pm \text { SD }} \\
\left.\left(\mu \mathrm{L} \cdot \mathbf{c m}^{-2}\right)\right]^{\mathrm{z}}\end{array}$ & $\begin{array}{c}\text { Spray coverage } \\
{[\text { mean } \pm \mathrm{SD}(\%)]}\end{array}$ & $\begin{array}{c}\text { Droplet density } \\
{[\text { mean } \pm \text { SD }} \\
\left.\left(\mathbf{n o} \cdot / \mathbf{c m}^{2}\right)\right]^{\mathrm{z}}\end{array}$ \\
\hline 3 & 10 & $0.24 \pm 0.12$ & $5.4 \pm 3.4$ & $26.9 \pm 26.2$ \\
3 & 20 & $0.49 \pm 0.37$ & $7.3 \pm 5.6$ & $29.9 \pm 29.1$ \\
3 & 30 & $0.66 \pm 0.58$ & $8.2 \pm 4.5$ & $32.1 \pm 30.2$ \\
3 & 40 & $0.66 \pm 0.58$ & $10.5 \pm 4.9$ & $22.6 \pm 17.6$ \\
4 & 10 & $0.46 \pm 0.24$ & $6.3 \pm 3.7$ & $20.7 \pm 18.2$ \\
4 & 20 & $0.77 \pm 0.30$ & $9.8 \pm 4.9$ & $22.8 \pm 21.9$ \\
4 & 30 & $1.25 \pm 0.39$ & $19.3 \pm 8.0$ & $43.5 \pm 28.0$ \\
4 & 40 & $1.74 \pm 0.48$ & $28.7 \pm 9.7$ & $46.5 \pm 20.4$ \\
5 & 10 & $0.58 \pm 0.26$ & $7.6 \pm 4.1$ & $23.6 \pm 21.4$ \\
5 & 20 & $0.75 \pm 0.21$ & $11.7 \pm 4.1$ & $23.0 \pm 17.5$ \\
5 & 30 & $1.15 \pm 0.35$ & $18.3 \pm 7.3$ & $33.1 \pm 21.5$ \\
5 & 40 & $1.55 \pm 0.36$ & $26.8 \pm 6.1$ & $42.5 \pm 20.9$ \\
6 & 10 & $0.43 \pm 0.14$ & $6.2 \pm 2.6$ & $24.9 \pm 23.3$ \\
6 & 20 & $0.76 \pm 0.19$ & $11.3 \pm 4.1$ & $26.3 \pm 18.8$ \\
6 & 30 & $1.09 \pm 0.30$ & $17.5 \pm 8.4$ & $41.8 \pm 29.8$ \\
6 & 40 & $1.28 \pm 0.32$ & $23.9 \pm 8.7$ & $47.7 \pm 26.6$ \\
& $5 \%$ LSD value & 0.28 & 3.9 & 14.5 \\
\hline
\end{tabular}

${ }^{2} 1 \mathrm{ft}=0.3048 \mathrm{~m}, 1 \mathrm{gal} /$ acre $=9.3540 \mathrm{~L} \cdot \mathrm{ha}^{-1}, 1 \mu \mathrm{L} \cdot \mathrm{cm}^{-2}=0.0314 \mathrm{fl} \mathrm{oz} / \mathrm{ft}^{2}, 1$ droplet $/ \mathrm{cm}^{2}=6.4516$ droplets $/$ inch $^{2}$

'Fisher's least significant difference (LSD) at $P<0.05$.

Table 4. Mean spray deposit, coverage, and droplet density at six different target heights inside 3-year-old 'Autumn Spire' red maple canopies for four application rates (ARs).

\begin{tabular}{|c|c|c|c|c|}
\hline $\begin{array}{l}\text { Target } \\
\text { ht (ft) }{ }^{\mathrm{z}} \\
\end{array}$ & $\begin{array}{c}\text { AR } \\
(\text { gal } / \text { acre })^{\mathrm{z}}\end{array}$ & $\begin{array}{l}\text { Spray deposit } \\
{[\text { mean } \pm \text { SD }} \\
\left.\left(\mu \mathrm{L} \cdot \mathrm{cm}^{-2}\right)\right]^{\mathrm{z}}\end{array}$ & $\begin{array}{l}\text { Spray coverage } \\
{[\text { mean } \pm \text { SD }(\%)]}\end{array}$ & $\begin{array}{c}\text { Droplet density } \\
{[\text { mean } \pm \text { SD }} \\
\left.\left(\text { no. } / \mathrm{cm}^{2}\right)\right]^{\mathrm{z}} \\
\end{array}$ \\
\hline 3 & 20 & $0.39 \pm 0.29$ & $4.8 \pm 2.5$ & $12.4 \pm 6.0$ \\
\hline 3 & 40 & $0.47 \pm 0.30$ & $6.9 \pm 4.8$ & $20.6 \pm 18.7$ \\
\hline 3 & 60 & $1.09 \pm 0.53$ & $10.9 \pm 5.3$ & $32.9 \pm 21.0$ \\
\hline 3 & 80 & $1.46 \pm 0.63$ & $17.8 \pm 10.8$ & $52.7 \pm 25.5$ \\
\hline 4 & 20 & $0.34 \pm 0.22$ & $5.0 \pm 2.8$ & $12.9 \pm 7.1$ \\
\hline 4 & 40 & $0.60 \pm 0.30$ & $11.4 \pm 7.2$ & $26.3 \pm 22.7$ \\
\hline 4 & 60 & $1.11 \pm 0.44$ & $18.9 \pm 10.0$ & $37.9 \pm 16.8$ \\
\hline 4 & 80 & $1.46 \pm 0.46$ & $25.5 \pm 13.1$ & $52.8 \pm 18.8$ \\
\hline 5 & 20 & $0.20 \pm 0.13$ & $3.9 \pm 1.8$ & $12.0 \pm 7.9$ \\
\hline 5 & 40 & $0.44 \pm 0.21$ & $8.5 \pm 6.1$ & $20.9 \pm 21.8$ \\
\hline 5 & 60 & $0.72 \pm 0.39$ & $12.5 \pm 6.4$ & $26.6 \pm 12.0$ \\
\hline 5 & 80 & $1.07 \pm 0.40$ & $19.5 \pm 12.5$ & $45.7 \pm 24.9$ \\
\hline 6 & 20 & $0.19 \pm 0.09$ & $4.7 \pm 3.7$ & $13.0 \pm 8.9$ \\
\hline 6 & 40 & $0.46 \pm 0.19$ & $9.7 \pm 7.1$ & $22.0 \pm 22.0$ \\
\hline 6 & 60 & $0.86 \pm 0.54$ & $18.5 \pm 7.1$ & $33.6 \pm 12.9$ \\
\hline 6 & 80 & $1.22 \pm 0.48$ & $29.2 \pm 16.8$ & $51.1 \pm 23.7$ \\
\hline 7 & 20 & $0.29 \pm 0.11$ & $5.8 \pm 2.4$ & $18.2 \pm 12.1$ \\
\hline 7 & 40 & $1.02 \pm 0.75$ & $12.7 \pm 6.3$ & $26.6 \pm 22.5$ \\
\hline 7 & 60 & $1.31 \pm 0.66$ & $23.0 \pm 8.0$ & $37.3 \pm 18.8$ \\
\hline 7 & 80 & $1.92 \pm 0.55$ & $30.5 \pm 12.0$ & $50.2 \pm 19.1$ \\
\hline 8 & 20 & $0.23 \pm 0.17$ & $4.3 \pm 2.1$ & $11.7 \pm 6.6$ \\
\hline 8 & 40 & $1.26 \pm 0.64$ & $24.3 \pm 12.6$ & $37.3 \pm 22.3$ \\
\hline 8 & 60 & $2.01 \pm 0.74$ & $33.3 \pm 16.3$ & $44.3 \pm 21.3$ \\
\hline 8 & 80 & $2.19 \pm 0.82$ & $36.8 \pm 22.2$ & $53.5 \pm 25.0$ \\
\hline \multicolumn{2}{|c|}{$5 \%$ LSD value ${ }^{\mathrm{y}}$} & 0.41 & 6.5 & 12.1 \\
\hline
\end{tabular}

than at the top. Also, the amount of foliage across the height of a canopy of 3-year-old liners was not uniform. To achieve uniform spray deposition across all heights and reduce spray usage in 3-year-old liners, half flow rate nozzles should be used at the top of the boom.

Spray COVERAge. The mean spray coverage on targets inside the canopy increased linearly as the application rate increased in both 2 - (Fig. 4A) and 3-year-old liners (Fig. 4B). The percentage coverage was nearly doubled when the application rate was doubled. With the same application rate, the spray coverage on leaves of 2-year-old liners was higher than the leaves of 3-year-old liners. For example, the mean spray coverage was $10.3 \%$ and $4.8 \%$ at a $20-\mathrm{gal} /$ acre application rate and was $22.7 \%$ and $12.4 \%$ at a $40-\mathrm{gal} /$ acre application rate inside the 2 - and 3 -year-old canopies, respectively. These results are similar to those for spray deposition.

Spray coverage was not significantly different on targets at heights of 4,5 , and $6 \mathrm{ft}$ for a particular application rate in the 2 -year-old liner test (Table 3). The lowest part of canopy at $3 \mathrm{ft}$ above the ground received significantly less spray coverage than the three uppermost parts of canopy (Table 3). For 3-year-old liners, the variation of spray coverage at all heights inside the canopy was not significant with the 20 -gal/acre application rate but was significant at three higher application rates (Table 4 ). The average amount of spray coverage on targets across the 7 - and 8-ft heights for 40-, 60-, and 80-gal/ acre application rate was 2.0, 1.9, and 1.5 times higher, respectively, than those across the 3-, 4-, 5-, and 6-ft heights. These results are also similar to those for spray deposition.

Droplet Density. The droplet density or number of droplets per unit area on 2-year-old liners was not significantly different between 10- and 20-gal/acre application rates and between the 30 - and 40 -gal/acre application rates (Table 3 and Fig. 5A). The average density on targets inside 2-year-old liner canopies was $23.7,24.9,37.8$, and 40.1 droplets/ $\mathrm{cm}^{2}$ when the application rate was $10,20,30$, and $40 \mathrm{gal} / \mathrm{acre}$, respectively. On the other hand, the droplet density inside 3-year-old liners increased linearly as the application rate 


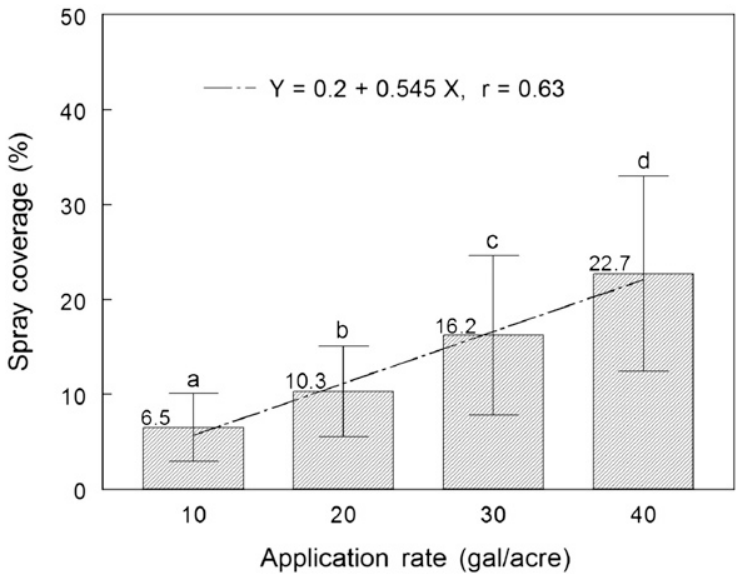

A

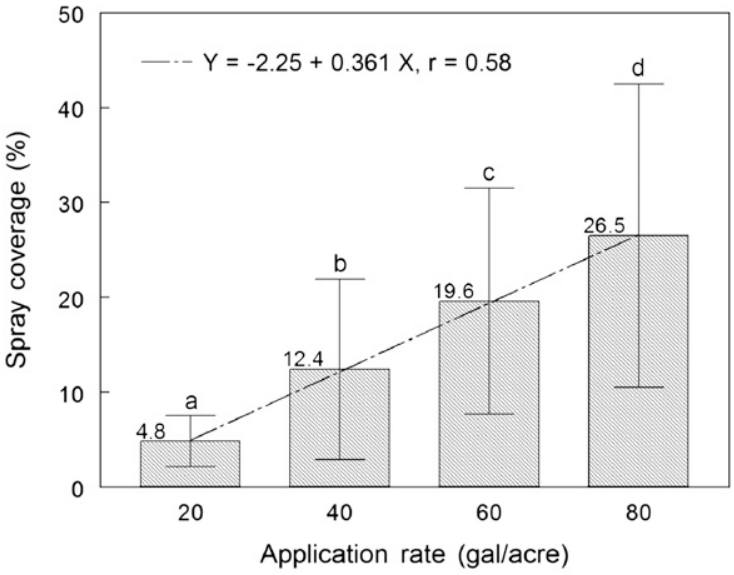

$\mathrm{B}$

Fig. 4. Mean spray coverage on samplers at different heights inside canopies for four application rates to treat (A) 2-year-old and (B) 3-year-old 'Autumn Spire' red maple liners. Error bars are sD for each treatment. Different lowercase letters on error bars present significant differences in means at $P<0.05 ; Y=$ spray coverage (percent), $X=$ application rate (gallons per acre), $r=$ coefficient of determination; $1 \mathrm{gal} / \mathrm{acre}=9.3540 \mathrm{~L} \cdot \mathrm{ha}^{-1}$.

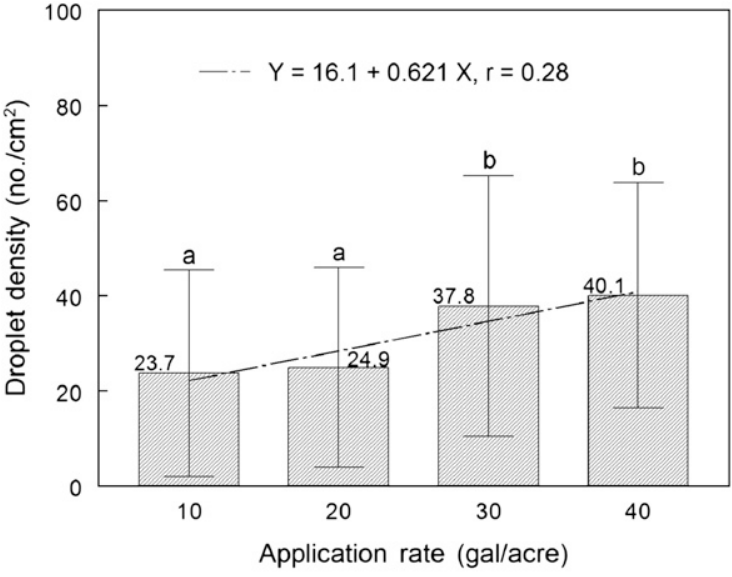

A

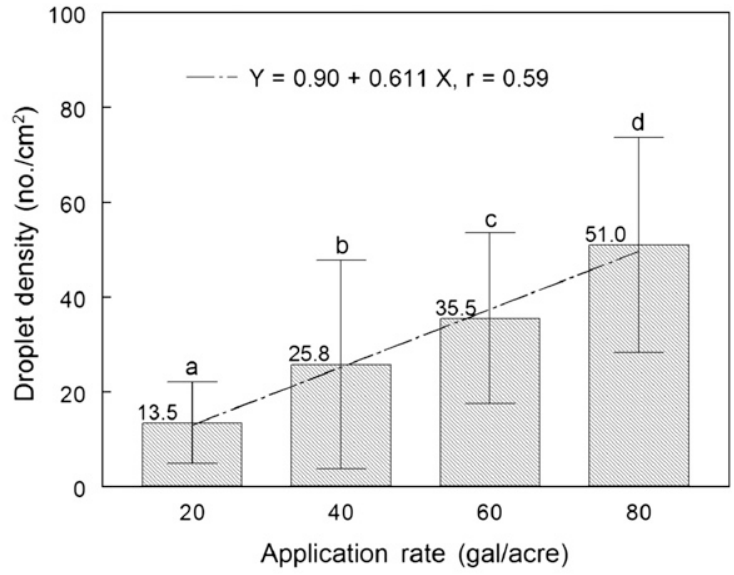

$\mathrm{B}$

Fig. 5. Mean droplet density on samplers at different heights inside canopies for four application rates to treat (A) 2-year-old and (B) 3-year-old 'Autumn Spire' red maple liners. Error bars are sD for each treatment. Different lowercase letters on error bars present significant differences in means at $P<0.05 ; Y=$ droplet density (number of droplets per square centimeter), $X=$ application rate (gallons per acre), $r=$ coefficient of determination; $1 \mathrm{gal} / \mathrm{acre}=9.3540 \mathrm{~L} \cdot \mathrm{ha}^{-1}, 1 \mathrm{droplet} / \mathrm{cm}^{2}=6.4516$ droplets $/$ inch $^{2}$.

increased (Table 4 and Fig. 5B). The average droplet densities on watersensitive papers inside 3 -year-old liner canopies were $13.5,25.8,35.5$, and 51.0 droplets $/ \mathrm{cm}^{2}$ when the application rates were $20,40,60$, and 80 gal/acre, respectively. However, the density was not as high as expected because many droplets overlapped after their deposition on water-sensitive papers and consequently the number of droplets was lowered. This can also be explained by the fact that the deposit sizes $\left(d_{\mathrm{V} 0.1}, d_{\mathrm{V} 0.5}, d_{\mathrm{V} 0.9}\right)$ are much greater than the actual in-flight droplet sizes ( $D_{\mathrm{V} 0.1}, D_{\mathrm{V} 0.5}$,
$D_{\text {V0.9) }}$ (Table 5). It was difficult for the DepositScan software to accurately measure the droplet density when over $30 \%$ area of a water-sensitive paper was covered by spray deposits. Therefore, for any droplet density with spray coverage greater than $30 \%$ reported in this paper might be artificially low.

The dv0.5 (also called volume median diameter) of deposits on targets inside 2 -year-old liner canopies was $2.5,2.3,2.6$, and 3.4 times the $D_{\text {V0.5 }}$ of actual droplets when the application rate was $10,20,30$ and 40 gal/acre, respectively. Similarly, the $d_{\mathrm{v} 0.5}$ of deposits on water-sensitive papers within 3-year-old liner canopies was $2.4,2.5,3.6$, and 4.6 times the $D_{\text {v0.5 }}$ of actual droplets when the application rate was 20,40,60, and $80 \mathrm{gal} / \mathrm{acre}$, respectively. Therefore, the actual number of droplets deposited on targets should be more than twice the number of deposits counted on targets.

Effective spray applications depend on the amount of spray deposits, the extent of coverage, and number of droplets on target leaves or collectors. Implicit in this fact is that a greater number of spray droplets per unit area should have a higher probability of 
reaching the critical threshold for effective pest control. The recommendation from a pesticide manufacturer (Syngenta Crop Protection, 2004) is that at least 20 to 30 droplets $/ \mathrm{cm}^{2}$ are needed for insecticide applications and 50 to 70 droplets $/ \mathrm{cm}^{2}$ for fungicide applications to provide satisfactory results. Droplet density of this recommendation may be higher than what is actually needed for particular pests, e.g., 30 droplets $/ \mathrm{cm}^{2}$ for control of black sigatoka ascospores (Mycosphaerella fijiensis) on banana (Musa spp. AAA group) leaves (Washington, 1997), 9 droplets $/ \mathrm{cm}^{2}$ for control of gypsy moth larvae (Lymantria dispar) on white oak (Quercus alba) leaves (Falchieri et al., 1995), and 9 droplets $/ \mathrm{cm}^{2}$ for control of african armyworm larvae (Spodoptera exempta) within grass (Poaceae) canopies (Hewitt and Meganasa, 1993). The mean volume droplet diameters for 2 and 3-year-old liners were $164 \mu \mathrm{m}$ from the spray applied at $20 \mathrm{gal} / \mathrm{acre}$ and $171 \mu \mathrm{m}$ from the spray applied at 40 gal/acre, respectively (Table 5 ). The $0.69 \mu \mathrm{L} \cdot \mathrm{cm}^{-2}$ deposit is equivalent to 298 droplets of $164 \mu \mathrm{m}$ deposited on 2 -year-old liners at the 20-gal/acre application rate and 263 droplets of $171 \mu \mathrm{m}$ deposited on 3 -year-old liners at the 40 -gal/acre application rate.

The $D_{\mathrm{V} 0.5}$ of droplets discharged from nozzles at four application rates ranged from 230 to $364 \mu \mathrm{m}$ and from 230 to $401 \mu \mathrm{m}$ to spray 2 - and 3 -yearold liners, respectively (Table 5 ). The droplet sizes for the 10 -gal/acre application rate to spray 2 -year-old liners and the $20-\mathrm{gal} /$ acre application rate to spray 3 -year-old liners are classified by the American Society of Agricultural Engineers Standard S-572.1 as medium droplets and droplet sizes for all other rates are classified as coarse droplets. The values of $D_{\mathrm{m}}$ ranged from 141 to $173 \mu \mathrm{m}$ for all applications (Table 5) and were more consistent than the values of $D_{\mathrm{V} 0.5}$ when the application rate changed from 10 to $40 \mathrm{gal} / \mathrm{acre}$ for the 2-year-old liner application and from 20 to $80 \mathrm{gal} / \mathrm{acre}$ for the 3-year-old liners. The droplet size data illustrates that the spray quality for different rates used for 2 - and 3-year-old liners were comparable for the nozzles and operating parameters used.

Sample images of spray deposits on water-sensitive papers at the $3-\mathrm{ft}$ height at different application rates inside 2 - and 3-year-old liners are represented in Fig. 6. Based on the above results on spray deposit, coverage, and droplet density and observation of

Table 5. Distributions of spray droplet diameters from nozzles measured with a particle/droplet image analysis system (VisiSizer and PIV; Oxford Lasers, Didcot, UK) in the laboratory and distributions of mean spray deposit diameters on water-sensitive papers inside canopies, which were measured with a custom-designed software "DepositScan" (Zhu et al., 2010). The distributions were for four different application rates (ARs) applied to 2- and 3-year-old 'Autumn Spire' red maple liners.

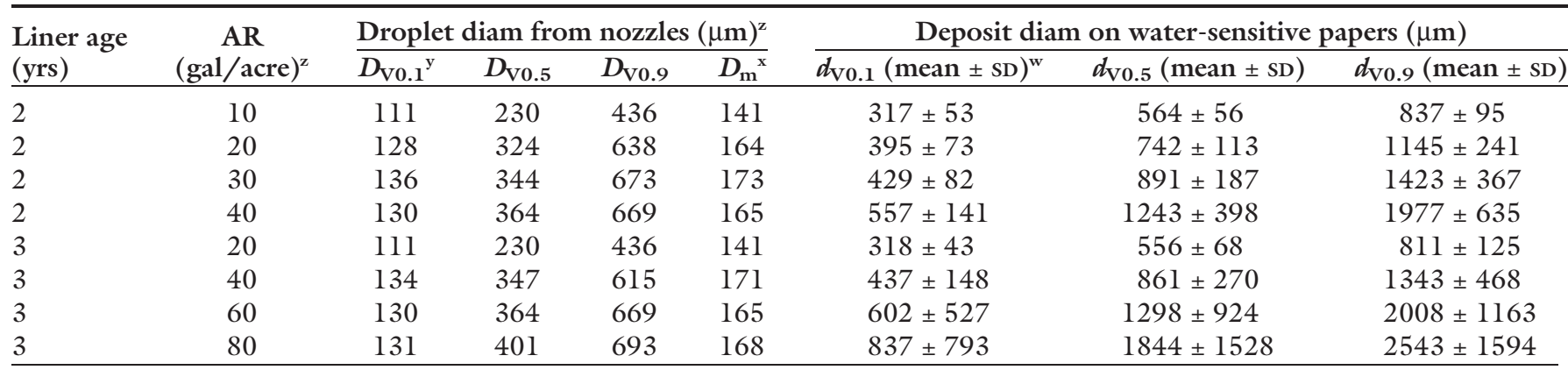

${ }^{\mathrm{z}} 1 \mathrm{gal} /$ acre $=9.3540 \mathrm{~L} \cdot \mathrm{ha}^{-1}, \mathrm{l} \mu \mathrm{m}=1$ micron.

${ }^{y} D_{\mathrm{V} 01}, D_{\mathrm{V} 0.5}$, and $D_{\mathrm{V} 0.9}$ are diameters that droplets of $10 \%, 50 \%$, and $90 \%$ total spray volume are smaller than these diameters, respectively.

${ }^{\mathrm{x}} \mathrm{D}_{\mathrm{m}}$ is the mean volume diameter calculated from the total volume of the spray divided by the total number of droplets.

${ }^{\mathrm{w}} d_{\mathrm{V} 0.1}, d_{\mathrm{V} 0.5}$, and $d_{\mathrm{V} 0.9}$ are diameters of spray deposits on water-sensitive papers with the same meaning of $D_{\mathrm{V} 0.1}, D_{\mathrm{V} 0.5}$, and $D_{\mathrm{V} 0.9}$
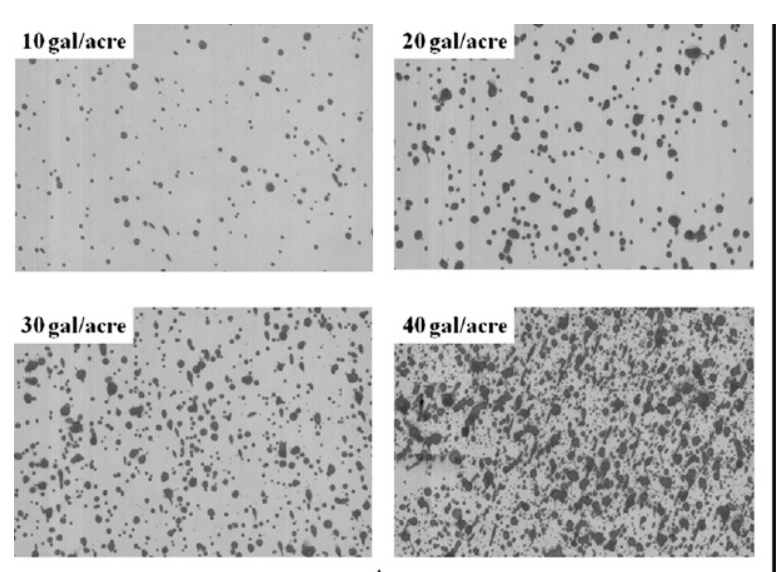

A
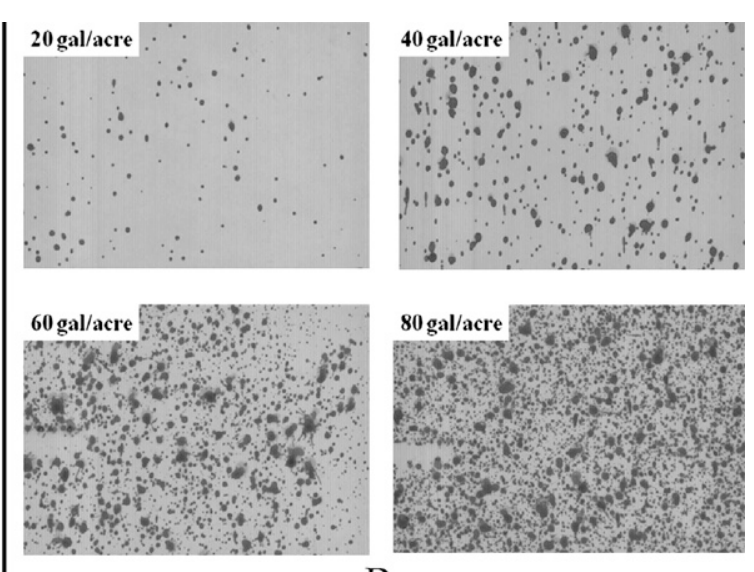

B

Fig. 6. Images of spray deposits on water-sensitive papers at $3 \mathrm{ft}(0.9 \mathrm{~m})$ height inside canopies of (A) 2-year-old and (B) 3-yearold 'Autumn Spire' red maple liners at four different application rates; $1 \mathrm{gal} / \mathrm{acre}=9.3540 \mathrm{~L} \cdot \mathrm{ha}^{-1}$. 
images of spray deposits shown on Fig. 6 , the sprays at the 20 -gal/acre or higher application rates for the 2-yearold liners and 40-gal/acre or higher application rates for the 3-year-old liners almost covered the entire surface of the target and were considered adequate for insect and disease control. However, the 40-gal/acre and 60- or 80-gal/acre application rates for 2 - and 3-year-old liners, respectively, suggest saturated deposition and runoff losses from less denser canopy.

SPRAY MODEL. An 'Autumn Spire' red maple liner is generally an ovoidal shape, and its height is proportional to its maximum width. Also, most of its branches grow upward and outward along its vertical axis and stretch out as an exponential curve. This branch outline allows an estimation of the tree volume as an exponential function of tree height. Since the amount of spray required for adequate deposition and coverage is determined by canopy volume, the exponential function to express this relationship of canopy volume between the spray application rate and liner height is given in Eq. [1]:

$$
Q=b_{0} e^{b_{1} H},
$$

where $Q$ is spray application rate (gallons per acre), $H$ is liner height (feet), and $b_{0}$ and $b_{1}$ are regression constants. Based on the results of this study, the optimal application rates to achieve adequate deposition and coverage for 6.6-ft-tall, 2 -year-old liners and 8.7-ft-tall, 3-year-old liners are between 20 and $30 \mathrm{gal} /$ acre and 40 and $50 \mathrm{gal} /$ acre, respectively. Substituting the midpoints (25 and $45 \mathrm{gal} / \mathrm{acre})$ of the application rates of these two ranges to Eq. [1], the values of $b_{0}$ and $b_{1}$ were obtained as 3.06 and 0.314 , respectively. In turn, substituting the values of $b_{0}$ and $b_{1}$ to Eq. [1] yields,

$$
Q=3.06 e^{0.314 H} \text {. }
$$

The optimal application rates calculated with Eq. [2] for liners of different heights are presented in Fig. 7. With these values, different application rates can be achieved by a combination of the number of nozzles in use and proper selection nozzle size. Also, these values calculated from Eq. [2] could be applied to other nursery crops with similar canopy density and shape as 'Autumn Spire' red maple liners.

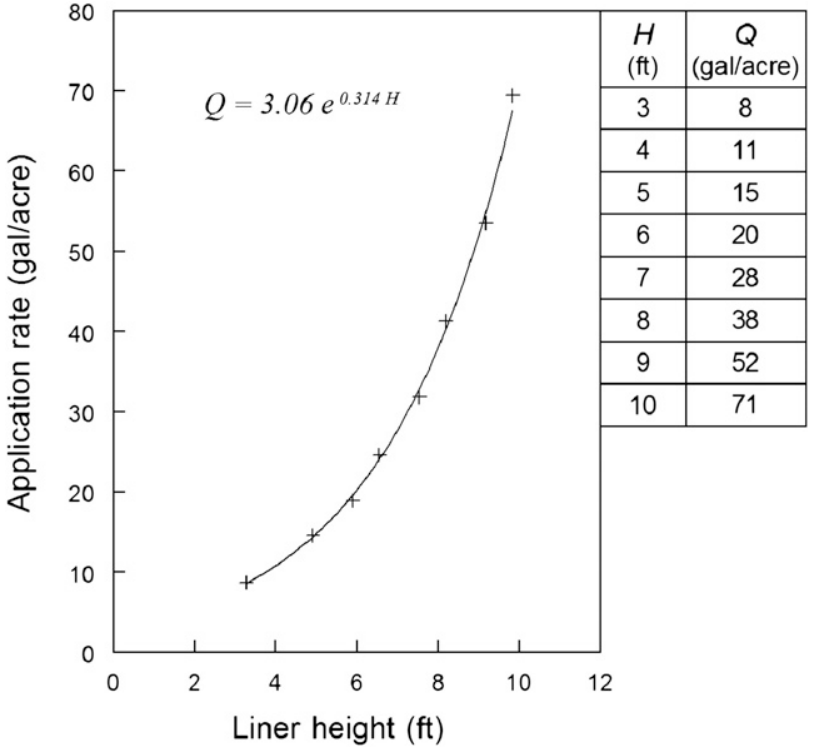

Fig. 7. Spray application rates needed for tree liners as an exponential function of liner heights based on the equation $Q=3.06 e^{0.314 H}$, where $H=$ liner height (feet) and $Q=$ application rate (gallons per acre); $1 \mathrm{ft}=0.3048 \mathrm{~m}, 1 \mathrm{gal} /$ acre $=9.3540 \mathrm{~L} \cdot \mathrm{ha}^{-1}$.

\section{Conclusions}

Spray deposition, coverage, and droplet density increased as the application rate increased for both 2 - and 3 -year-old liners. Four nozzles at a minimum 20-gal/acre application rate and six nozzles at a minimum 40-gal/ acre application rate produced adequate application sprays on targets inside canopies of 2-and 3-year-old liners at heights of 6.6 and $8.7 \mathrm{ft}$, respectively.

Based on the shape of the liner canopies, an exponential equation was derived from these results to estimate the spray application rate required for different tree liner heights. Optimal application rates determined to provide adequate spray deposition and coverage inside liner canopies were $8,20,38$, and $71 \mathrm{gal} /$ acre when liner heights were $3,6,8$, and $10 \mathrm{ft}$, respectively.

\section{Literature cited}

Bache, D.H. and D.R. Johnstone. 1992. Microclimate and spray dispersion. Ellis Horwood, New York, NY.

Derksen, R.C., C.R. Krause, R.D. Fox, and R.D. Brazee. 2004. Spray delivery to nursery trees by air curtain and axial fan orchard sprayers. J. Environ. Hort. 22:17-22.

Falchieri, D., K. Mierzejewski, and S. Maczuga. 1995. Effects of droplet density and concentration on the efficacy of Bacillus thuringiensis and carbaryl against gypsy moth larvae (Lymantria dispar L.). J. Environ. Sci. Health B 30:535-548.

Fare, D.C. 2006. Container size and initial trunk diameter effects growth of Acer rubrum L. during production. J. Environ. Hort. 24:18-22.

Fisher, R.W. and D.R. Menzies. 1976. Effect of spray droplet density and exposure time on the immobilization of newlyhatched oriental fruit moth larvae. J. Econ. Entomol. 69:438-440.

Hewitt, A.J. and T. Meganasa. 1993. Droplet distribution densities of a pyrethroid insecticide within grass and maize canopies for the control of Spodoptera exempta larvae. Crop Prot. 12:59-62.

Hollingsworth, C.S. 2010. Pacific northwest insect management handbook. Oregon State Univ., Corvallis.

Ingham, R., J. McMorran, C.M. Ocamb, J.W. Pscheidt, and M. Putnam. 2010. Pacific northwest plant disease handbook. Oregon State Univ., Corvallis.

Krause, C.R., H. Zhu, R.D. Fox, R.D. Brazee, R.C. Derksen, L.E. Horst, and R.H. Zondag. 2004. Detection and quantification of nursery spray penetration and off-target loss with electron beam and conductivity analysis. Trans. Amer. Soc. Agr. Eng. 47:375-384.

Syngenta Crop Protection. 2004. Watersensitive paper for monitoring spray distribution. Bul. Ag CH-4002. Syngenta Crop Protection, Basel, Switzerland.

U.S. Department of Agriculture. 2007. Agricultural chemical usage 2006 nursery 
and floriculture summary. U.S. Dept. Agr., Natl. Agr. Stat. Serv., Agr. Stat. Board, Washington, DC.

U.S. Department of Agriculture. 2010. 2009 Census of horticultural specialties. U.S. Dept. Agr., Natl. Agr. Stat. Serv., Agr. Stat. Board, Washington, DC.

Washington, J.R. 1997. Relationship between the spray droplet density of two protectant fungicides and the germination of Mycosphaerella fijiensis ascospores on banana leaf surfaces. Pestic. Sci. 50:233239.

Zhu, H., M. Salyani, and R.D. Fox. 2010. A portable pixel recognition system for evaluating the distribution of spray deposits. Paper No. 1008502. American Society of Agricultural and Biological Engineers, St. Joseph, MI.

Zhu, H., R.C. Derksen, H. Guler, C.R. Krause, R.H. Zondag, and H.E. Ozkan. 2006. Foliar deposition and off-target loss with different spray techniques in nursery applications. Trans. Amer. Soc. Agr. Biol. Eng. 49:325-334.

Zhu, H., R.H. Zondag, R.C. Derksen, M. Reding, and C.R. Krause. 2008. Influence of spray volume on spray deposition and coverage within nursery trees. J. Environ. Hort. 26:51-57. 